\title{
0 princípio feminino Sateré-Mawé e as relações de gênero
}

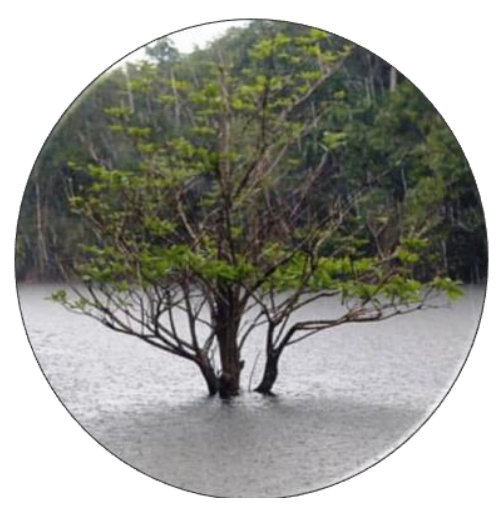

Iraildes Caldas Torres ${ }^{1}$

Refletir sobre o princípio primeiro da etnia Sateré-Mawé, sua nascente geradora enquanto povo e seres constitutivos da humanidade requer que voltemos o nosso olhar para a sua ontogênese. Trata-se da busca cognoscível e de inteligibilidade acerca da ontologia dessas criaturas e da economia dos seus dispositivos.

A mitologia Sateré-Mawé dá conta de que a origem e a humanidade desse povo advêm da força de uma mulher que, vivendo ainda em uma dimensão encantada, pré-humana, teve seu filho morto por dois irmãos seus que não aceitaram sua gravidez gerada por uma cobrinha macho. Expulsa de casa pelos irmãos Anhyã-muasawyp criou sozinha seu filho longe deles, o qual recebeu o nome de Kahu'ê. Já crescido, o menino pede à mãe para voltar ao Nusokén ${ }^{2}$ - e região encantada onde viviam seus tios, já que o mundo dos humanos ainda não tinha sido criado - para comer o fruto da castanheira que seus tios comiam. A

\footnotetext{
1 Doutora em Antropologia Social pela PUC-SP e Pós-Doutora pela Université Lumière Lyon 2, França. É professora da Universidade Federal do Amazonas.

2 Anhyã-muasawyp era a dona do Nusokén. Seus irmãos tomaram dela por ocasião da expulsão.
} 
mãe não permitiu, até que um dia o menino resolveu ir sozinho àquela região encantada, ocasião em que foi morto pelos vigias dos tios.

Anhyã-muasawyp pegou o corpo de seu filho e levou para a área do rio Marau, longe do Nusokén. Lá retirou o olho esquerdo do filho e o plantou de onde nasceu o Waranã-Hôp, o falso guaraná. Depois arrancou o olho direito e o plantou em terras pretas, no oeste de Nusokén. "Dele nasceu o verdadeiro guaraná, o Waraná Sése. Este é o bom guaraná, e Anbyá-muasawyp conformou-se com sua criação" (YAMÃ, 2007, p. 56). Depois, em conversa com o menino, como se ele ainda estivesse vivo, a mãe profetizou nos seguintes termos:

Tu, meu filho, serás a maior bênção da natureza. Tu farás o bem a todo homem. Tu serás poderoso. Tu livrarás os homens das doenças e curarás as doenças dos que o procurarem e acreditarem no seu bom poder. Todas as almas cansadas chegarão a você, e não negarás o pedido de socorro. Todos os fracos serão seus seguidores e você lhes devolverá a força da juventude (IBIDEM, p.56).

Está aqui o eixo teleológico da vida Sateré-Mawé, seu vigor e longevidade. O guaraná é uma força integradora da sociabilidade, do coletivo e das decisões políticas. É nucleadora das relações sociais e de poder, está presente nos atos cruciais de elaboração da vida social dos sateré-sawé. Essa concepção não é destituída de importância para a compreensão da ontogênese dessa etnia, e a ela retornarei mais adiante.

Ao dar prosseguimento à narrativa sobre a origem dos Sateré-Mawé atente-se para o fato de que Kahu'ê cujo olho direito gerou o guaraná bom está no princípio gerador da vida desse povo. A narrativa mitológica informa que depois da morte do filho de Anbyã-muasanyp, ela viajou com ele e o enterrou debaixo de uma árvore de Abiu'rana, "perto do rio Seremu'yt, o rio mágico, local situado na cabeceira do rio Marau [...] e deixou um de seus ajudantes para vigiar. O nome desse ajudante era Karaxué, um passarinho de canto muito bonito" (YAMÃ, 2007, p. 57).

A ordem da mãe do menino morto era de que esse passarinho a avisasse caso ele ouvisse algum barulho vindo da sepultura. Depois de alguns dias, o passarinho-vigia ouviu um barulho que saía da sepultura. Logo voou para avisar 
Anbyã-muasawyp. Ela veio, abriu a sepultura e dela saiu o Kuatá, macaco da noite. Ela assoprou no olho do macaco e o amaldiçoou, ele passou a ser um agouro dentro da mata. Depois ela fechou a sepultura e derramou o sumo de uma folha mágica sobre a cova.

Os dias foram passando e, conforme combinado, Karaxuê saia voando para avisar a mãe do morto toda vez que ouvia um barulho vindo da sepultura. $\mathrm{Na}$ segunda vez ela veio e retirou de lá o Kuaty, seguido do Kaiarana e do Kaititú. Ela "assoprou sobre o Kaiarana e o amaldiçoou, dizendo que ele nunca seria comido. Quanto ao Kuaty e o Kaititú ela os abençoou e os mandou lá para as bandas do rio Abacaxis" (IBIDEM, p. 58). Outra vez a mãe foi chamada, abriu a sepultura e de lá saiu o macaco Zóg-Zóg. Ela o expulsou e assim procedeu com outros animais que saíram depois dele. Enfim, da sepultura saíram o taiasú, o veado, a capivara, o macaco-prego e muitos outros animais.

Por fim, Karaxué ouviu um ruído estrondoso vindo da sepultura e amedrontado foi chamar Anbyã-muasanyp que o acalmou pelo caminho enquanto pegava ervas perfumadas para levar. De acordo com o nosso autor,

Ao chegar no local, abriu novamente a sepultura e dali saiu uma criança: o primeiro indivíduo mawé, o povo do guaraná. Esse menino era o filho de Anbyã-muasanyp que havia renascido: era moreno, tinha um belo sorriso e cabelos longos como à noite. Anbyã-muasanyp deu-lhe o nome de Mary-Aypók, que quer dizer 'homem verdadeiro' ou 'originador'. Ela pegou com todo o cuidado a criança, colocou-a no colo e pôs em sua boca dentes feitos de terra. Em seguida, afiou-os com os dentes da piranha para que pudesse mastigar bem os alimentos (por isso os mawé tem tradição de afiar os dentes) (YAMÃ, 2007, p. 60).

Segue a narrativa dizendo que a mulher lavou as mãos, os pés e a cabeça do menino, ensinou-lhe uma língua que Tupana indicou e que era falada só por pessoas do bem que seguisse Anhyã-muasawyp. Trata-se da língua Sateré-Mawé, falada pelos guerreiros do fogo ${ }^{3}$. Bem, enquanto a mãe lavava Mary-Aypók outra

\footnotetext{
3 Sateré-Mawé é um nome composto que evoca tanto o aspecto de apego e respeito pela etnia aos seres da natureza, quanto o aspecto humano. Por isso, o primeiro nome sateré evoca a lagarta de fogo e é em referencia ao clã mais importante da tribo. O segundo nome mawé que significa papagaio falante, curioso, é em homenagem aos bichos da floresta.
} 
criança saiu do buraco da sepultura, era o irmão gêmeo do "originador", a quem ela deu o nome de Wasary-Pót. Tupana que assistiu a essa mulher "dar origem a uma nova raça de seres, homens de verdade [...], ficou contente. E para que o planeta fosse povoado por novos seres, fez com que surgisse também vários outros povos e raças noutras partes" (IBIDEM, p. 60). E, assim, foram surgindo outros povos indígenas como os munduruku, pavinkintin, mura e muitos outros. Tupana, antes de partir prometeu ao povo de Anbyã-muasanyp uma terra e um país onde haveria fortuna e prosperidade. Tupana partiu, mas a mulher ficou bem empoderada, pois seus descendentes teriam terra para morar.

Anhyã-muasawyp cuidou bem dos seus filhos que cresceram e foram se assenhorando da floresta, mataram seus tios que baniram sua mãe no passado, pois eles tinham se tornado maus. Conforme indica o nosso autor eles,

\footnotetext{
Casaram com as mais belas filhas dos bichos da floresta. Mary-Aypók casou com a linda Abút-Piá, filha do papagaio, dando origem, assim, ao significado da palavra Mawé: 'papagaio falante', e este passou a ser o maior símbolo do povo. Wasary-Pót casou-se com Hano'onapiä'bop, filha da arara-piranga, e seus filhos dariam as mais belas penas para os seus descendentes se embelezarem (YAMÃ, 2007, p. 61).
}

Termina a narrativa dizendo que foi assim que surgiu o verdadeiro povo Sateré-Mawé, descendentes de Mary-Aypók e Wasary-Pót, filhos de Anbyãmuasawyp, ressurgidos do corpo de Kabu'ê.

Todo o edifício conceptual, político-social, ético e moral dos povos indígenas está ancorado na oralidade das histórias passadas de geração a geração. O objeto de estudo desta análise está centrado numa narrativa sobre a arché ou origem do povo Sateré-Mawé. Existem outras narrativas distribuídas em três gêneros: mitos, lendas e fábulas. Os Sateré-Mawé não estão interessados em distinguir se as narrativas são falsas ou verdadeiras. Todos esses gêneros apoiamse em historias que trazem ensinamento para a vida e para todo o seu sistema ético-político-social. Essas histórias são radicalmente diferentes, como diz Eliade (2007). 
Ao tema do mito deve haver um olhar multidimensional na medida em que nos deparamos com um conhecimento vivo, dinâmico, que embebe a vida e dá sentido fulgurante ao regime de verdade desses povos indígenas. Trata-se de um conhecimento sempre renovador e desafiante que não empobrece, nem fragmenta o sentido da vida humana. Para Unger (2000, p. 56), "o reencantamento do mundo significa descobrirmos aquilo que nos constitui, reencantar o mundo é poder novamente ter uma vivência da realidade que não se reduza à reificação”.

O mito nos leva a pensar. Compreendemos o mito em sua perspectiva ontológica é uma forma de teatralização do mundo. Ele tem força porque ele narra, sente. $\mathrm{O}$ mito é uma verdade, não a verdade da racionalidade, é uma leitura provisória do mundo, mas, nem por isso, há divórcio entre mito e razão. O mito possui uma racionalidade própria que é diferente daquela do europeu.

Observe-se que os mitos não são narrados por qualquer pessoa e nem em qualquer lugar. Isto porque o mito não quer contar uma mentira. Leonor da Silva (45), morador da comunidade indígena Santa Maria do Urupadi, que compõe a amostra desta pesquisa, deixa claro o fato de "que as histórias Sateré-Mawé não são cantadas fora da aldeia, da comunidade" (entrevista/ 2012).

Não se trata de uma sacralização dos mitos, mas sim do lugar instituído para operar com essa racionalidade. Assim como as sociedades ocidentais possuem seus lugares apropriados para realizar a difusão do conhecimento, através de seus professores nas escolas, nas universidades e similares, da mesma forma os indígenas tem seus lugares e seus agentes disseminadores de seus conhecimentos. Os velhos são os agentes transmissores do conhecimento nas aldeias. Nos últimos tempos os professores indígenas também assumem esse papel na escola. Lévi-Strauss (1991) lembra que o mito é a historia de um povo, é a identidade primeira e mais profunda de uma coletividade.

Uma vez vivente, fundador, o mito coloca-se como um demiurgo norteador do comportamento, da virtude, solicitude e do apanágio da vida em sociedade. No caso do mito examinado neste estudo, chama-me a atenção, o 
princípio feminino ordenador dos acontecimentos que redundaram no evento de origem dos Sateré-Mawé. A mulher aparece como chave central, uma força capaz de atos grandiosos que fundam não só os seres viventes, mas também todo o sistema moral e estético de um povo. Vimos na narrativa que, ao dar conselho ao filho de cujo olho direito brotou o guaraná, ela fazia uma prédica em torno de valores, comportamento e ajuda ao outro, remetendo para a realização do bem na terra. A estética aparece na textura da plumagem da arara-piranga cujas cores vermelho e preto compõem a tonalidade "oficial" da etnia.

Quando perguntei a uma indígena da comunidade Molongotuba, outra unidade amostral desta pesquisa, se os homens tratam bem suas mulheres, ela disse o seguinte: " o homem sateré é muito bom para com a mulher, cuida dela. Aqueles que batem e bagunçam com a mulher são influenciados pela bebida e levam bolo na mão" " (Leonice, 50 anos, entrevista/ 2012). Note-se que a nossa informante reconhece que as mulheres são bem tratadas pelos companheiros, embora exista violência contra a mulher na sua comunidade, assunto que será abordado em outra parte deste livro.

Krüger (2005) reconhece que as comunidades primitivas possuíram sim uma linha matriarcal em algum momento de sua história. E, o fato de os homens Sateré-Mawé tratarem bem suas mulheres, especialmente por ocasião da gestação e do resguardo de parto, pode sim estar associados a esse vestígio ancestral, mas é mais provável que "o homem tenha cuidado com a mulher parida de parto, em torno de 120 dias para evitar que a criança seja atingida pelo espírito do mal e dos animais. Não é porque ele está preocupado com a vida da mulher" (Henrique Pereira, 33 anos, entrevista/2012).

É pertinente e elucidativo o relato de Henrique Pereira, professor indígena da Comunidade Santa Maria do Urupadi, quanto ao cuidado verdadeiro pelo recém-nascido e não propriamente pela mulher em situação de parto. Mas, não podemos negar que há nessa prática um respeito para com a mulher. $\mathrm{O}$

\footnotetext{
${ }^{4}$ A informante refere-se ao castigo aplicado aos homens que praticam violência doméstica na comunidade. Eles levam palmadas nas mãos, bolo na linguagem dos índios, que é uma forma encontrada pelas mulheres para conter a violência.
} 
homem assume o trabalho da mulher para evitar que ela pegue peso fazendo extravagância que prejudique sua saúde.

Toda a contextura da tradição Sateré-Mawé está ligada ao princípio feminino. O sakpó, bebida derivada do guaraná, tem princípio feminino. São as mulheres que se ocupam da feitura do sakpó e que introduzem o recipiente contendo a bebida (cuia) no lugar onde são realizadas as reuniões ou outras atividades coletivas. São quatro rodadas de sakpó e em cada uma delas o individuo pode fazer um pedido. É bebido na cuia que é um artefato retirado da árvore cuieira e fabricado em forma de cumbuca. Essa "cuia começa a girar pelo lado direito que é a forma positiva de relação com a natureza, é uma forma de estabelecer relações econômicas visando à prosperidade" (Vivaldo, 42 anos, entrevista/ 2012).

Para além do sabor de uma bebida revigorante o sakpó engendra um significado político, perceptível no seu uso coletivo e nos tipos de acontecimentos nos quais ele é servido. Sônia Vilácio (39 anos), umas das mulheres ouvidas nesta pesquisa, chama a atenção para o fato de que,

\footnotetext{
O sakpó é uma atividade das mulheres, mas elas só ralam o guaraná e servem a bebida na cuia quando na reunião. Onde tem sakpó enche de gente porque envolve uma ação coletiva, política. E as mulheres estão sempre nessas reuniões de decisões políticas. Não pode jogar fora, deixar estragar o sakpó, ele é respeitado, é sagrado (entrevista/ 2012).
}

O que se torna notável, por conseguinte, é que o aspecto político do sakpó possui um significado mais amplo do que só as tomadas de decisão. Política para os propósitos dos Sateré-Mawé em uso ritualístico do sakpó envolve uma dimensão de pertença tribal incomensurável. O valor e a sua eficácia, como diz Uggé (1993, p. 28), “estão no momento de tomá-lo juntos e reviver, reforçar a memória tribal".

O sakpó é o elo da sociabilidade do povo Sateré-Mawé. Contar história, por exemplo, que é algo muito sério de transmissão dos conhecimentos tradicionais e que não pode ser contada em qualquer lugar, é momento propício para tomar o sakpó. A história é contada numa rodada por uma pessoa mais 
velha, tomando sakpó, e não tem pressa, é de forma preguiçosa. Para Vivaldo Valente dos Santos (42 anos), Sateré-Mawé do rio Andirá ouvido nesta pesquisa,

O sakpó é sagrado. Começa a ser bebido pelo lado direito porque o direito representa a harmonia, o positivo, a ordem cósmica. Bebe-se o sakpó em conjunto para procurar a graça da natureza, a vida em paz na família [...]. O sateré acredita muito na natureza que é o seu universo. Existem duas formas de tomar o sakpó: a primeira é a forma coletiva tomado em círculo; a outra é feita pelo tuxaua que dá individualmente. Depois põe a cuia num suporte. O sakpó tem princípio feminino, veio de uma mulher (entrevista/ 2012).

É perceptível na fala de Vivaldo tanto o aspecto de integração com o cosmos que o sakpó promove quanto o lado da sociabilidade e da tomada de decisões políticas, esta ultima simbolizada na figura do tuxaua que serve individualmente a bebida do alto de sua autoridade. Evoca-se, assim, as relações de poder para se chegar a resultados positivos e satisfatórios para o povo. $\mathrm{O}$ suporte do sakpó de onde o tuxaua serve as pessoas recebe o nome de patauí "que pela mitologia representa, junto com a cuia, a estrutura do mundo onde nós vivemos; é a terra com as águas onde vivem os homens" (UGGÉ, 1993, p. 28).

O Guaraná é social, econômico e cultural. Em outras palavras, é um produto que possui valor simbólico e comercial. De acordo com Teixeira (2005, s/p), “os Sateré-Mawé se autodenominam 'os filhos do guaraná, tendo essa planta grande importância para a organização social e econômica da população. São eles os inventores da cultura do guaraná, que já domesticaram a trepadeira silvestre e criaram a técnica para seu beneficiamento".

Para podermos compreender o alcance simbólico do sakpó é preciso ter presente o princípio feminino presente nele, tal como sinalizado por Vivaldo dos Santos. Primeiramente é preciso compreender que o tempo mítico tece o tempo presente, o Kairós, grávido de ação (TORRES, 2009). Depois, é interessante e sugestivo percebermos a constituição das relações de gênero por dentro da ontogênese do povo Sateré-Mawé. Está na narrativa sobre a origem desse povo o eclipse de gênero, que só enxergamos se pusermos lupa, o que nem sempre o fazemos e assim contribuímos para permanecer imperceptível. Anbyã-muasawyp é a 
mulher da qual se desdobrou a criação do povo Sateré-Mawé, aquela que, no princípio de tudo, antes da existência da humanidade, vivia no nusoquén que é o paraíso dos seres encantados inumano propriamente dito.

A mulher é alfa e ômega, está no princípio e no fim, tal como revela uma das mulheres inquiridas nest4e estudo, a saber: “o sakpó é uma prática coletiva. Roda-se a cuia até onde começou, com a mulher que começou a rodar a cuia. Quando a cuia chegar à mulher que ralou o guaraná ela tem que está vazia”. (Henrique Pereira, entrevista/2012).

Anbyã-muasawyp também era um ser encantado que, de característica feminina, também se transformava em pássaro para voar e chegar mais rápido nos lugares, possuindo também, possuía também qualidade de xamã na medida em que sabia manipular as ervas da floresta. Mostra-se performática e multifacetada tais quais as mulheres deste Planeta Terra que executam várias tarefas ao mesmo tempo, possuindo, pois, uma visão periférica das coisas que as rodeia sem perder o seu foco principal.

Esta é, pois, uma perspectiva de gênero que marca a posição política da mulher na sociedade indígena. Cabe-nos questionar os paradigmas dominantes que excluíram a mulher e a perspectiva feminina de ver o mundo social. Perrot (2007) considera que essa situação está associada ao silêncio sobre elas nos relatos, que ocorreu pelo fato de elas terem sido excluídas e inviabilizadas nos documentos. Trata-se dos relatos elaborados a partir do contato em meio aos acontecimentos da conquista.

A decodificação assume, por assim dizer, a forma de reabilitação e/ou resgate da simbologia feminina no contexto indígena Sateré-Mawé. O feminino é o inicio e o fim. É, também, ao mesmo tempo o ponto de convergência e união da tribo presente no ritual do sakpó, elaborado e comandado pelas mulheres. No sakpó, como pontua Nascimento (2010, P. 30), “as mulheres têm um espaço que é exclusivamente seu e não pode ser substituído pelo homem porque isto implicaria numa ruptura natural daquilo que é próprio de cada um dentro [...] das relações que se travam na sociedade étnica”. 
Inexiste, a meu ver, uma partilha dos bens simbólicos dos Sateré-Mawé sem a presença do princípio feminino. Não existe a partilha sem o objeto simbólico, sem a ontologia das criaturas, esse (com) sentir originário que constitui os Sateré-Mawé. O exemplo da tucandeira ${ }^{5}$ é aqui iluminador deste tema de gênero que nos ocupa nesta análise. Em diálogo com Antenor Garcia Meneses (59 anos), pajé da comunidade Santa Maria do Urupadi que compõe a amostra desta pesquisa, ficou patente o fato de que "a tucandeira é também feminina, ela vem de uma mulher. Tanto é que, quando o rapaz mete a mão na luva, ele é levado por duas mulheres" (entrevista/ 2012).

A voz autoral dos sujeitos que vivem a experiência cotidiana com o mito dá o tom ontológico das relações de gênero fecundando a vida do povo SateréMawé. Atente-se para o fato de que são dois sujeitos da pesquisa que exercem funções hierárquicas importantes que afirmam haver o princípio feminino nos rituais deste povo. Vivaldo Valente dos Santos, que é sacerdote católico de origem Sateré-Mawé, identifica no sakpó o princípio feminino, assim como Antenor Meneses que é o pajé de seu povo em Molongotuba também vê esse princípio no ritual da tucandeira e na própria representação dessa formiga tucandeira. De acordo com a narrativa do pajé,

A tucandeira foi trazida do encante ${ }^{6}$ pelo Tatu Grande (Tatu Canastra). As tucandeiras que vieram do encante são mulheres. É por isso que os jovens metem a mão na tucandeira, porque ele é atraído pela mulher. Quem começa a meter a mão na luva é porque já está buscando mulher para viver (Antenor, entrevista/ 2012).

Esta é uma outra expressão das relações de gênero que tece e transveste a cultura Sateré-Mawé: a sexualidade estritamente associada à reprodução humana. Após submeter-se ao ritual da tucandeira o rapaz está apto a casar e constituir família. Desde a tenra idade tanto o menino quanto a menina sateré-sawé são

\footnotetext{
${ }^{5}$ Espécie de formiga muito venenosa utilizada no ritual da tucandeira que marca a passagem da infância para a idade adulta do homem Sateré-Mawé.

${ }^{6}$ Nusokén ou Nosokén é o lugar onde habitam os seres encantados como os companheiros do fundo e os animais que não vivem na condição dos humanos. A esse lugar os Sateré-Mawé dão o nome de encante
} 
preparados para as responsabilidades futuras pertinentes à constituição de suas famílias. E, o ápice dessa preparação é o ritual de passagem, cuja entrega do menino à tucandeira é feita pelas mulheres. Ou seja, as mulheres que sabem o que é sofrer dor, porque passam pelo evento da maternidade, tem segurança de que os homens sairão ilesos das mordidas da formiga, sairão também mais fortes e muito mais fortes e corajosos do que antes.

O princípio feminino da formiga Tucandeira está inerente não só no âmbito da sexualidade, mas também enquanto representação simbólica de força e energia vital das mulheres que enfrentam a dor de parto e as dificuldades da vida com coragem e "valentia". É essa força "uterina" que permite ao menino suportar a dor dilacerante proveniente das picadas ou mordidas da Tucandeira. Como diz Rinne (1988), a força das mulheres tal qual a de Medéia, é impressionantemente forte e muito mais resistente do que a força dos homens.

O interessante, neste sentido, é percebermos a existência de um princípio feminino que subjaz à cultura Sateré-Mawé como uma força que impulsiona os atos e as práticas sociais de sua gente. Essa representação e seus significados simbólicos abrangem desde a pulsão da sexualidade, quando o rapaz começa a se interessar por mulher, até o primado da fortaleza incomparável da mulher.

A luva utilizada no ritual de passagem masculino assume a representação de um útero e a tucandeira é uma mulher que fecunda novos filhos, os quais ressurgem corajosos e valentes depois do rito de passagem. Esse aspecto é importante e remete a um exame mais detido, o que seria demasiado longo discutir aqui. Interessa-me aqui assinalar, de forma mitigada, o fato de que as relações de gênero engendram e se estabelecem na cultura Sateré-Mawé do inicio ao fim, com todas as suas simetrias e assimetrias. 


\section{Referências}

ELIADE, Mircea. Mito e realidade. Traduzido por Paola Civelli. São Paulo: Perspectiva, 2007

LEVI- STRAUSS, Claude. O cru e o cozido. Traduzido por Beatriz Perrone Moisés. São Paulo: Brasiliense, 1991

KRUGER, Marcos Frederico. Amazônian: mito e literatura. Manaus: Edua, 2003

NASCIMENTO, Solange Pereira. Vida e trabalho da mulher indigena: o protagonismo da tuxana Baku na comunidade Sabu-apé, Iranduba/ AM. Dissertação de Mestrado. Manaus: UFAM, 2010

PERROT, Michelle. Minha história das mulheres. Traduzido por Ângela M. C. Corrêa. São Paulo: Contexto, 2007

RINNE, Olga. Medeia: o direito à ira e ao ciúme. Traduzido por Margit Martincic e Daniel Camarinha da Silva. São Paulo: Cultrix, 1998

TEIXEIRA, Pery (org). Sateré-Mawé: retrato de um povo indígena. Relatório de pesquisa. Manaus: UFAM, 2005

TORRES, Iraildes Caldas. Arquitetura do poder: memória de Gilberto Mestrinho. Manaus: Editora da Universidade Federal do Amazonas, 2009

UGGÉ, Henrique. As bonitas historias Sateré-Mawé. Manaus: Secretaria de Educação do Estado do Amazonas, 1993

UNGER, Nancy Mangabeira. O encantamento do humano: ecologia e espiritualidade. São Paulo: Loyola, 2000

YAMÃ, Yaguarê. Sehaypóri: o livro sagrado do povo Sateré-Mawé. São Paulo: Peirópolis, 2007. 